\title{
ANALISIS MARGIN PEMASARAN DARI SALURAN PEMASARAN IKAN HIAS DI ENAM PASAR BOGOR (Survei di Kota /kab. Bogor Provinsi Jawa Barat)
}

\author{
Oleh \\ Sobariah , Ganjar Wiryati \\ Dosen Jurusan Penyuluhan Perikanan Sekolah Tinggi Perikanan
}

\begin{abstract}
ABSTRAK
Pendapatan yang tinggi adalah tujuan akhir dari pelaku utama dalam hal ini pembudidaya ikan baik ikan konsumsi maupun ikan hias, namun demikian pada kenyataannya para pembudidaya ikan khususnya ikan hias belum dapat menikmati keuntungan sesuai dengan yang mereka harapkan, justru para pedagang di berbagai level baik itu pengumpul maupun pengecer yang menikmati keuntungan lebih baik dari pada para pembudidaya yang dengan susah payah mengelola usahanya dengan berbagai resiko yang dijalaninya.

Salah satu penyebab terjadinya kesenjangan penerimaan keuntungan adalah karena sistem pemasaran yang masih terlalu panjang dimana dari pembudidaya ke pedagang pengumpul, pedagang pengumpul ke pedagang besar, pedagang besar ke pengecer, dari pengecer baru sampai ke konsumen akhir dalam hal ini pembeli ikan hias.

Untuk mengetahui seberapa besar pengaruh margin pemasaran ikan hias di beberapa pasar yang ada di wilayah Bogor, maka perlu diadakan peneiltian tentang margin pemasaran dari saluran pemasaran ikan hias di enam pasar yang ada di sekitar Bogor. Dikarenakan keterbatasan waktu dan biaya dari peneliti, maka penelitian tentang margin pemasaran ikan hias hanya dilakukan di enam pasar yang dominan. Tujuan Penelitian a) Ingin mengetahui pangsa pasar diterima penjual, pembudidaya dari harga yang dibayarkan konsumen. b) Ingin mengetahui berapa penjual yang memanfaatkan pasar yang ada di kota Bogor. c) Ingin mengetahui perbandingan margin pemasaran dari saluran distribusi ikan hias pada enam pasar di Bogor. Metodologi penelitian lebih pada pendekatan sistem, fungsi dan kegunaan pemasaran komoditas perikanan secara Konseptual dan operasional dengan hasil perhitungan bahwa Margin Pemasaran yang dihitung dari dua jenis ikan hias pada enam pasar menunjukkan bahwa marjin Pemasaran terendah sebesar Rp. 24; disaluran 1, Rp.48, berada pada saluran 2, dan terdapat pada pasar 3 dan 4 yaitu Pasar Parung dan Pasar Anyar, hal ini menunjukan bahwa komoditas ikan Cupang dan Koki adalah merupakan jenis komoditas yang efisien untuk komoditas ikan hias tersebut. Untuk Margin Pemasaran (MP) tertinggi berada pada posisi saluran 3 di pasar 2 dan 6, yaitu Margin Pemasaran sebesar RP.4.850 di saluran 3 pada pasar 2 yaitu pada Depo Baranang Siang, dan margin pemasaran sebesar Rp.3.600 berada pada posisi saluran 3 di pasar 6 atau Pasar Ciawi, yang berarti bahwa komoditas ikan hias Koki dan Cupang menunjukan jenis ikan hias yang tidak efisien bagi sipembudidaya, karena penerimaan pembudidaya lebih kecil dari pedagang pengumpul maupun pedagang ecaran
\end{abstract}

Kata kunci : harga, pasar, perikanan, selisih 


\section{PENDAHULUAN}

\section{Latar Belakang}

Pendapatan yang tinggi adalah tujuan akhir dari pelaku utama dalam hal ini pembudidaya ikan baik ikan konsumsi maupun ikan hias, namun demikian pada kenyataannya para pembudidaya ikan khususnya ikan hias belum dapat menikmati keuntungan sesuai dengan yang mereka harapkan, justru para pedagang di berbagai level baik itu pengumpul maupun pengecer yang menikmati keuntungan lebih baik dari pada para pembudidaya yang dengan susah payah mengelola usahanya dengan berbagai resiko yang dijalaninya.

Salah satu penyebab terjadinya kesenjangan penerimaan keuntungan adalah karena sistem pemasaran yang masih terlalu panjang dimana dari pembudidaya ke pedagang pengumpul, pedagang pengumpul ke pedagang besar, pedagang besar ke pengecer, dari pengecer baru sampai ke konsumen akhir dalam hal ini pembeli ikan hias.

Apabila regulasi pemasaran ikan sudah diatur sedemikian rupa sehingga ada standarisasi harga sesuai ukuran maupun kualitas produk yang dihasilkan maka kemungkinan para pelaku utama yaitu pembudidaya ikan hias akan dapat menikmati keuntungan sesuai dengan pengorbanan yang telah dikeluarkan, untuk itu perlu adanya pengaturan agar pendapatan para pembudiaya dapat sesuai harapan mereka.

Nilai jual ikan hias di berbagai pasar juga berbeda satu dengan lainnya, hal ini disebabkan banyak faktor yang mempengaruhi salah satunya adalah panjangnya rantai tata niaga yang menyebabkan perbedaan harga jual ikan hias dari satu pasar ke pasar lainnya.
Untuk mengetahui seberapa besar pengaruh margin pemasaran ikan hias di beberapa pasar yang ada di wilayah Bogor, maka perlu diadakan peneiltian tentang margin pemasaran dari saluran pemasaran ikan hias di enam pasar yang ada di sekitar Bogor. Dikarenakan keterbatasan waktu dan biaya dari peneliti, maka penelitian tentang margin pemasaran ikan hias hanya dilakukan di enam pasar yang dominan.

Umumnya motivasi pembudidaya dan penjual ikan hias adalah memperoleh uang tunai melalui penjualan hasil produksinya dalam upaya memenuhi kebutuhan hidup keluarga nya sehari-hari. Semua itu ditentukan oleh tinggi rendahnya harga serta besarnya margin pemasaran, sehingga dalam meningkatkan pemasarannya dapat dicapai apabila penyebab margin pemasarannya diketahui.

Disini akan lebih mengarah pada margin pemasaran yang artinya bahwa margin pemasaran atau tataniaga komoditas perikanan ikan hias adalah selisih antara harga dari dua tingkat rantai pemasaran atau selisih harga yang dibayarkan di tingkat pengecer (konsumen) dengan harga yang diterima oleh pembudidaya sebagai pelaku utama. Dengan kata lain tingkat margin pemasaran merupakan perbedaan harga ditingkat konsumen (harga yang terjadi karena perpotongan kurva penawaran primer/primary supply dengan permintaan turunan/derived demand ,(A.Rahim,2002)

Komponen margin pemasaran terdiri dari biaya-biaya yang diperlukan lembaga-lembaga pemasaran untuk melakukan fungsi-fungsi pemasaran yang disebut dengan biaya pemasaran atau biaya fungsional (fungsional cost) dan keuntungan (profit) lembaga pemasaran . Sistem pemasaran dianggap efisien apabila 
memenuhi syarat 1) mampu menyampaikan hasil dari petani produsen (pembudidaya) kepada konsumen dengan biaya semurah-murahnya, dan 2). Mampu mengadakan pembagian yang adil dari keseluruhan harga yang dibayar dari konsumen akhir kepada semua pihak yang telah ikut serta dalam kegiatan produksi dan pemasaran barang (A.Rahim, 2002) . Panjang pendeknya saluran pemasaran yang dilalui oleh suatu hasil produksi komoditas perikanan tergantung pada beberapa 54actor antara lain: jarak antara produsen kekonsumen, cepat tidaknya produksi rusak. Produk yang sifatnya cepat rusak harus segera diterimakan konsumen. Dengan demikian saluran produk tersebut mengehendaki saluran distribusi yang pendek dan cepat. Hastuti (2007). Pada dasarnya terdapat dua sistem pokok dalam pengumpulan informasi yang dibutuhkan yaitu: meningkatkan disiplin dan memberikan dasar bagi pengambilan keputusan.(Basu Swastha, 2002).

\section{Perumusan Masalah}

Bagaimana margin pemasaran dapat mengukur, pangsa pasar yang diterima oleh pebudidaya dari harga yang dibayarkan konsumen akhir. Biaya-biaya apa saja dalam menyalurkan komoditas perikanan seperti biaya angkut, biaya penimbangan, pembersihan dan retribusi serta bagaimana keuntungan lembaga pemasaran yang melaksanakan pemasaran komoditas dari produsen ke konsumen.

\section{Tujuan Penelitian}

a) Ingin mengetahui pangsa pasar diterima penjual, pembudidaya dari harga yang dibayarkan konsumen.

b) Ingin mengetahui berapa penjual yang memanfaatkan pasar yang ada di kota Bogor.

c) Ingin mengetahui perbandingan margin pemasaran dari saluran distribusi ikan hias pada lima pasar di Bogor

\section{METODOLOGI PENELITIAN}

\section{Kerangka Konseptual/definisi sistem informasi manajemen, pemasaran, margin (konsep pemasaran)}

\section{A). Definisi Sistem Informasi Manajemen \\ B). Sistem adalah kumpulan dari organ/perangkat yg berguna untuk memproses sesuatu yang memiliki tujuan tertentu.}

C). Sistem Informasi Manajemen Adalah kunci dari bidang yang menekankan financial dan personal manajemen.

D). Usaha adalah : Kegiatan dengan mengerahkan tenaga, pikiran atau badan untuk mencapai suatu maksud.

E).Pemanfaatan:Dalam Bashu Swastha informasi sangat mempengaruhi penggunaannya dan dapat membantu dalam manajemen

\section{Definisi operasional}

\section{Pemasaran:}

Dalam penelitian ini pemasaran memainkan peran untuk meningkatkan laju hasil produksi ke konsumen yang mencakup enam pasar 


\section{Pemanfaatan}

Dalam

penelitian

Pengusaha/pembudidaya memanfaatkan

fasilitas pasar yang ada di Bogor dimana terdapat informasi yang dapat memenuhi kriteri-kriteria penelitian tentang margin pemasaran ikan hias Sebagai alat pengumpulan data yang pokok. Penelitian survai ini menggunakan alat analisis yang meliputi analisis ekonomi tentang margin pemasaran, denganng terdiri dari biaya pemasaran, margin keuntungan, nisbah margin keuntungan, analisis kolerasi harga dan analisis elastisitas, transmisi harga yaitu sebagai berikut:

$\mathrm{Mj} \quad=\mathrm{Psi}-\mathrm{Pb}$, atau $\mathrm{mj}=\mathrm{bti}+\mathrm{I}$ $\mathrm{I}=\mathrm{Mji}-\mathrm{bti}$

Total margin pemasaran adalah: $\mathrm{Mj}=$ mji atau $\mathrm{Pr}-\mathrm{Pt}$

Keterangan :

mji = margin pada kelembagaan pemasaran tingkat ke-i

Psi = harga jual lembaga pemasaran tingkat ke $-\mathrm{i}$

$\mathrm{Pbi}=$ harga beli lembaga pemasaran tingkat ke-i

bti. = biaya pemasaran lembaga pemasaran tingkat ke $\mathrm{i}$

I $=$ keuntungan lembaga

pemasaran tingkat ke-i

$\mathrm{mj} \quad=$ totial marjin pemasaran

$\mathrm{Pr}=$ harga pada tingkat eksportir(pengumpul)

$\mathrm{Pt}=$ harga pada tingkat petani/pembudidaya sebagai produsen.

Untuk analsis nisbah margin

keuntungan, secara matematis dapat dituliskan sebagai berikut $=\underline{I}$.

Bti

\section{Populasi dan Sampling}

Populasi dalam penelitian ini adalah pemilik Usaha kecil menengah tentang komoditas ikan hias yang berada di lima pasar di kota Bogor Sedangkan sebagai Sampelnya, diambil secara Acak sederhana ( sample random sampling ${ }^{l}$ ). Sampel Untuk mewakili Populasi jumlah pemilik/penjual jenis komoditas ikan hias sebagai responden ${ }^{2}$.

\section{Teknik Pengumpulan data}

Teknik pengumpulan data dalam penelitian ini, untuk data primer data diperoleh dengan menggunakan daftar pertanyaan dalam bentuk kuisioner kepada responden dan wawancara mendalam pada informen berkopenten di enam pasar yang terpilih di kota /Kab.Bogor, juga menghimpun data dan informasi yang relevan dan mendukung penelitian, termasuk didalamnya studi kepustakaan sebagai data skunder untuk mendukung data primer.

\section{Teknik Analisa Data}

Teknis analisa data yang digunakan secara deskriptif kuantitatif, yang bertujuan untuk menggambarkan hasil analisis penelitian. Didukung dengan pendekatan kualitatif. Data diolah dengan tabulasi data, dan komputer yang kemudian disimpulkan.

\section{HASIL DAN PEMBAHASAN}

\section{Lembaga pemasaran}

Pergerakan hasil ikan hias dari produsen atau pembudidya sampai pada konsumen pada dasarnya menggambarkan pengumpulan maupun penyaluran/ penyebaran. Seperti halnya perputaran ikan hias yang ada di enam pasar di Bogor, Saluran ikan hias melibatkan beberapa 
lembaga pemasaran yaitu Pasar Parung, Pasar Anyar, pasar Dramaga, pasar Ciawi, Depo Cibinong dan Depo Baranang Siang Bogor, Pasar Penyaluran komoditas ikan hias yang terdapat pada enam pasar di kabupaten dan kota Bogor dilakukan oleh pedagang ikan hias yang langsung dilakukan oleh pembudidaya itu sendiri dan ada pula yang memang murni sebagai pedagang ikan hias. Komoditas yang di distribusikan diantaranya nampak dalam Tabel 1 berikut ini :

Tabel 1: Jenis Ikan hias dan produksi yang ada di enam pasar perhari

\begin{tabular}{|c|c|c|c|c|c|c|c|c|c|c|c|}
\hline NO & Jenis Ikan & Ukuran & Produksi & NO & Jenis Ikan & Ukuran & Produksi & NO & Jenis Ikan & Ukuran & Produksi \\
\hline 1 & KOKI & $1-2$ inc & 50.000 & 31 & Discus & $3 \mathrm{~cm}$ & 20.000 & 63 & Brownsmut & 5 inc & 7.500 \\
\hline 2 & comet & $10 \mathrm{~cm}$ & 20.000 & 32 & Lobster & $5 \mathrm{inc}$ & 5.000 & 64 & Ambasis & $5 \mathrm{~cm}$ & 750 \\
\hline 3 & Koy & $10 \mathrm{~cm}$ & 100.000 & 33 & Discus & $5 \mathrm{~cm}$ & 100.000 & 65 & $\begin{array}{l}\text { Sebra } \\
\text { Hongkong }\end{array}$ & $1-2$ inc & 1.000 \\
\hline 6 & $\begin{array}{l}\text { arwana } \\
\text { silver }\end{array}$ & $40 \mathrm{~cm}$ & 150 & 34 & Blue Carri & $1-2 \mathrm{inc}$ & 100.000 & 66 & Denis onik & $2 \mathrm{~cm}$ & 750 \\
\hline 7 & $\begin{array}{l}\text { arwana } \\
\text { irian }\end{array}$ & $10 \mathrm{~cm}$ & 200 & 35 & Black neon & $2 \mathrm{~cm}$ & 50.000 & 67 & $\begin{array}{l}\text { Brownsmut } \\
\text { albino }\end{array}$ & $7 \mathrm{~cm}$ & 750 \\
\hline 8 & $\begin{array}{l}\text { arwana } \\
\text { golden red }\end{array}$ & $20 \mathrm{~cm}$ & 100 & 36 & Golden tetra & $7 \mathrm{~cm}$ & 25.000 & 68 & pink tall & $4 \mathrm{~cm}$ & 750 \\
\hline 9 & $\begin{array}{l}\text { arwana } \\
\text { super red }\end{array}$ & $20 \mathrm{~cm}$ & 50 & 37 & Black ghost & $4 \mathrm{~cm}$ & 7.000 & 69 & pink tall & $\begin{array}{l}10-15 \\
\mathrm{~cm}\end{array}$ & 25.000 \\
\hline 10 & $\begin{array}{l}\text { palmas } \\
\text { albino }\end{array}$ & $2 \mathrm{~cm}$ & 2000 & 38 & Irian Terian & $\begin{array}{l}10-15 \\
\mathrm{~cm}\end{array}$ & 1.000 & 70 & $\begin{array}{l}\text { blue } \\
\text { Ceribarb }\end{array}$ & $7 \mathrm{~cm}$ & 120.000 \\
\hline 11 & $\begin{array}{l}\text { Arwana } \\
\text { banjar }\end{array}$ & $2 \mathrm{~cm}$ & 50 & 39 & $\begin{array}{l}\text { Remirezy } \\
\text { balon }\end{array}$ & $7 \mathrm{~cm}$ & 1.200 & 71 & $\begin{array}{l}\text { Neon Api } \\
\text { Albino }\end{array}$ & $7 \mathrm{~cm}$ & 15.000 \\
\hline 12 & $\begin{array}{l}\text { palmas } \\
\text { cerri }\end{array}$ & $1,5 \mathrm{inc}$ & 5.000 & 40 & Botia & $7 \mathrm{~cm}$ & 2.000 & 72 & Blue cerri & $7 \mathrm{~cm}$ & 25.000 \\
\hline 13 & $\begin{array}{l}\text { palmas } \\
\text { biru }\end{array}$ & $\mathrm{L}$ & 1.000 & 41 & $\begin{array}{l}\text { Leovad } \\
\text { dania }\end{array}$ & $7 \mathrm{~cm}$ & 7.500 & 73 & $\begin{array}{l}\text { blue } \\
\text { ceribarb }\end{array}$ & $7 \mathrm{~cm}$ & 2.000 \\
\hline 14 & oscar & $2-3 \mathrm{~cm}$ & 150 & 42 & patin albino & $7 \mathrm{~cm}$ & 5.000 & 74 & Brownsmut & $7-10 \mathrm{~cm}$ & 20.000 \\
\hline 15 & Louhan & M & 200 & 43 & Blue Star & $7-10 \mathrm{~cm}$ & 750 & 75 & $\begin{array}{l}\text { Refid } \\
\text { salam }\end{array}$ & $\begin{array}{l}7-10 \\
\mathrm{~cm}\end{array}$ & 15.000 \\
\hline 16 & Guppy & $\mathrm{M}$ & 30.000 & 45 & Srigunting & $7-10 \mathrm{~cm}$ & 100.000 & 76 & Serpe & M & 25.000 \\
\hline 17 & $\begin{array}{l}\text { Lemon } \\
\text { yellow }\end{array}$ & M & 2.500 & 46 & Blue ice & $\begin{array}{l}7-10 \\
\mathrm{~cm}\end{array}$ & 1.000 & 77 & Lele albino & M & 2.000 \\
\hline 18 & Remonbiru & M & 150 & 47 & Negroberlian & $5 \mathrm{~cm}$ & 750 & 78 & koi metalic & M & 20.000 \\
\hline 19 & Manfis & M & 3.000 & 48 & Blue jowwel & $7 \mathrm{~cm}$ & 750 & 79 & irian terian & M & 50000 \\
\hline 20 & $\begin{array}{l}\text { Manfis } \\
\text { indukan }\end{array}$ & 3 inc & 2.500 & 49 & $\begin{array}{l}\text { Reinbow } \\
\text { Feacoc }\end{array}$ & M & 25.000 & 80 & Headscener & & 2.000 \\
\hline 21 & $\begin{array}{l}\text { gurame } \\
\text { padang }\end{array}$ & 2 inc & 100 & 50 & Kongotetra & $5-7$ inc & 2.000 & & & & \\
\hline 22 & Neon tetra & M & 1.500 & 51 & Red tails & 6 inc & 15.000 & & & & \\
\hline 23 & pelati coral & M & 1.500 & 52 & Silver Dolar & $2-3$ inc & 25.000 & & & & \\
\hline 24 & Perot & M & & 54 & Red & $5-7$ inc & & & & & \\
\hline
\end{tabular}




\begin{tabular}{|l|l|l|l|l|l|l|l|l|l|l|} 
& Albino & & 800 & & Sumatera & & 2.000 & & \\
\hline 25 & Perot biasa & 2 inc & 5.000 & 55 & Barbir & 7 inc & 20.000 & & & \\
\hline 26 & Rednos & 5 inc & 2.000 & 57 & Oscar batik & L & 100.000 & & & \\
\hline 27 & $\begin{array}{l}\text { Black } \\
\text { molli }\end{array}$ & 5 inc & 100.000 & 58 & $\begin{array}{l}\text { moa (belut } \\
\text { hias) }\end{array}$ & & 5.000 & & & \\
\hline 28 & Aligator & 2 inc & 4.000 & 59 & Gabus & & 2.000 & & & \\
\hline 29 & $\begin{array}{l}\text { cupang } \\
\text { biasa }\end{array}$ & 3 inc & 250.000 & 60 & sino dencis & & 15.000 & & & \\
\hline 30 & $\begin{array}{l}\text { cupang } \\
\text { giand }\end{array}$ & 4 inc & 15.000 & 62 & Chenopoma & $7 \mathrm{~cm}$ & 120.000 & & & \\
\hline
\end{tabular}

Sumber data pasar 2011 diolah

\section{Kondisi Pasar}

Dari hasil survey menunjukkan bahwa ikan hias yang banyak dijual di pasaran dan banyak diminati pada beberapa daerah yang ada di kota/ Kabupaten Bogor, adalah ikan yang harganya murah dan bentuk dari ikan tersebut sangat menarik perhatian para pencinta ikan hias. Adapun pasar-pasar di kabupaten dan kota Bogor yang dijadikan tempat penelitian adalah depo Cibinong, Depo Baranangsiang,Pasar Parung, pasar Anyar, pasar Darmaga dan pasar Ciawi

Dari tabel 1 diatas, dapat dilihat Proses penyaluran produk sampai keluar wilayah Bogor, akan tetapi lebih banyak diwilayah Bogor dan sekitarnya. Pencinta ikan hias yang ada di Bogor tak dipengaruhi musim, hal ini mengingat setiap hari dipasar ini semua jenis ikan bisa dijual, dari semua jenis ikan hias yang ditawarkan. Seperti halnya permintaan dan penawaran ikan hias yang ada di Bogor baik Kabupaten/kota, dimana ikan hias ini dapat dijadikan acuan dalam menghitung margin pemasaran. Dengan pengertian secara ekonomi adalah harga dari sekumpulan jasa pemasaran/tataniaga yang merupakan interaksi antara permintaan dan penawaran produk ikan hias. Dari data tersebut dapat dilihat pemanfaatan pasar sebagai penyaluran barang hasil pembudidaya ikan hias.

Dari data jenis ikan hias pada enam lokasi pasar ikan hias nampak terlihat proses penyaluran barang dari produsen ikan hias sampai kekonsumen akhir. Pergerakan hasil perikanan dari produsen sampai kekonsumen tersebut pada dasarnya menggambarkan pengumpulan maupun penyerabaran barang- barang sebelum diterima konsumen yang terlebih dahulu mengalami proses pengumpulan dan proses penyebaran pedagang besar $(\mathrm{Pb} /)$ sehingga titik akhir pengumpulan dan penyebaran. Perantara dalam pemasaran sangat membantu produsen (pembudidaya ikan hias) dalam menyalurkan produk untuk sampai kekonsumen berdasarkan jenis, jumlah, harga, tempat dan waktu saat dibutuhkannya. Berdasarkan pemantauan dilapangan ternyata pembudidaya lebih suka menjual langsung pada pengumpul atau tengkulak yang ada diwilayah tempat budidaya ikan hias, untuk dijual pada pedagang besar dan pedagang pengecer yang ada dipasar pada wilayah kota/kabupaten yang selanjutnya akan dijual kekonsumen akhir. Panjangnya rantai pemasaran ini menyebabkan besarnya biaya-biaya pemasaran dan margin keuntungan menjadi rendah pada masing- 
masing lembaga pemasaran sehingga bagian yang diterima oleh pembudidaya akan semakin kecil, serta harga ditingkat konsumen akhir menjadi lebih tinggi. Dari tabel 3 tersebut menunjukkan bahwa jenis ikan hias yang dijual pada enam lokasi pasar terdapat perbedaan harga jual, karena dari enam pasar yang didata terdapat beberapa tahapan atau katagori dari jenis ikan yang sama tetapi berbeda harga. Kategori data tersebut diantaranya : 1) terdapat dua jenis ikan hias yang sama tetapi berbeda harga, di enam pasar, yaitu ikan Koki dan Ikan Cupang.; 2) terdapat satu jenis ikan yang sama berbeda harga di lima pasar yaitu ikan hias manfis dengan size ML dan M.;3) terdapat enam Jenis ikan yang sama tetapi harga berbeda pada empat pasar yaitu Oscar, Aligator,Neon Tetra, Rednos,Louhan, dan manfis indukan.;4) terdapat tujuh jenis ikan yang sama di tiga pasar yaitu Comet, Koy,Oscar albino, Palmas biru, Remon/lemon biru, Perot biasa dan Red Tails, yang ke 5), terdapat dua puluh tiga jenis ikan hias yang sama pada dua pasar, sisanya satu jenis satu pasar.

\section{Margin Pemasaran}

Margin Pemasaran ikan hias pada penelitian ini dilihat pada komoditas yang sama di enam pasar dengan perbedaan harga jual yaitu terdapat dua jenis ikan hias yang sama dari enam lokasi pasar adalah ikan hias Koki dan ikan hias Cupang. Perbedaan harga ini dikarenakan : jarak pasar, biaya yang dikeluarkan.oleh produsen ataupun pedagang pengumpul hingga sampai ke pasar untuk sampai kekonsumen akhir. berikut daftar harga dan jenis ikan yang sama dari enam pasar.

Seperti disampaikan sebelumnya, bahwa dari enam lokasi pasar ternyata memiliki jenis ikan yang sama atau menjual ikan hias.yang sama yaitu Ikan Koki dan Ikan Cupang. Nampak dalam Tabel 4 berikut distribusi harga dari seluruh pasar sebagai berikut.:

Tabel 4. Harga dan Jenis Ikan Hias yang Sama Pada 6 Pasar

\begin{tabular}{|c|c|c|c|c|c|c|c|}
\hline \multirow{3}{*}{$\begin{array}{l}\mathrm{N} \\
\mathrm{o}\end{array}$} & \multirow{3}{*}{ Pasar } & \multicolumn{4}{|c|}{ Ikan KOKI } & \multicolumn{2}{|c|}{$\begin{array}{c}\text { IKAN CUPANG } \\
\text { BIASA }\end{array}$} \\
\hline & & \multicolumn{6}{|c|}{ Harga } \\
\hline & & $\begin{array}{c}\text { pembudiday } \\
\mathrm{a}\end{array}$ & $\begin{array}{c}\text { pengumpu } \\
1\end{array}$ & penjual & $\begin{array}{c}\text { pembudiday } \\
\text { a }\end{array}$ & $\begin{array}{c}\text { pengumpu } \\
1\end{array}$ & penjual \\
\hline 1 & Depo Cibinong & 1.500 & 2.400 & 2.500 & 2.000 & 3.200 & 5.000 \\
\hline 2 & $\begin{array}{l}\text { Depo } \\
\text { Baranangsiang }\end{array}$ & 10.000 & 15.000 & 20.000 & 3.000 & 4.500 & 7.500 \\
\hline 3 & pasar Parung & 600 & 1.000 & 2.000 & 100 & 200 & 1.000 \\
\hline 4 & Pasar Anyar & 1.000 & 1.500 & 2.000 & 2.000 & 2.500 & 4.000 \\
\hline 5 & Pasar dramaga & 1.000 & 1.500 & 2.000 & 1.000 & 1.750 & 2.500 \\
\hline 6 & Pasar ciawi & 600 & 2.000 & 3.500 & 100 & 10.000 & 5.000 \\
\hline
\end{tabular}

Sumber : data 2011 diolah 
Tabel 5 : Perbandingan Margin Pemasaran dari ke tiga saluran pemasaran ikan hias Koki, dan Cupang pada Enam Pasar di Bogor.

\begin{tabular}{|c|c|c|c|c|c|c|}
\hline URAIAN & \multicolumn{3}{|c|}{ KOKI } & \multicolumn{3}{|c|}{ CUPANG } \\
\hline \multirow{4}{*}{$\begin{array}{c}\text { pasar } 1 \\
\text { dari pembudidaya } \\
\text { dari konsumen } \\
\text { Margin Pemasaran(MP) }\end{array}$} & saluran 1 & saluran 2 & saluran 3 & saluran 1 & saluran 2 & saluran 3 \\
\hline & 1.140 & 2.280 & 2.067 & 1.520 & 2.432 & 3.800 \\
\hline & 1.500 & 2.400 & 2.500 & 2.000 & 3.200 & 5.000 \\
\hline & 360 & 120 & 433 & 480 & 768 & 1.200 \\
\hline \multirow{3}{*}{$\begin{array}{c}\text { pasar } 2 \\
\text { dari pembudidaya } \\
\text { dari konsumen } \\
\text { Margin Pemasaran(MP) }\end{array}$} & 7.600 & 14.200 & 15.150 & 2.280 & 3.420 & 5.700 \\
\hline & 10.000 & 15.000 & 20.000 & 3.000 & 4.500 & 7.500 \\
\hline & 2.400 & 800 & 4.850 & 720 & 1.080 & 1.800 \\
\hline \multirow{3}{*}{$\begin{array}{c}\text { pasar 3 } \\
\text { dari pembudidaya } \\
\text { dari konsumen } \\
\text { Margin Pemasaran(MP) }\end{array}$} & 456 & 952 & 1408 & 76 & 152 & 760 \\
\hline & 600 & 1.000 & 2.000 & 100 & 200 & 1.000 \\
\hline & 144 & 48 & 592 & 24 & 48 & 240 \\
\hline \multirow{3}{*}{$\begin{array}{c}\text { pasar } 4 \\
\text { dari pembudidaya } \\
\text { dari konsumen } \\
\text { Margin Pemasaran(MP) }\end{array}$} & 456 & 952 & 1.408 & 76 & 152 & 760 \\
\hline & 600 & 1.000 & 2.000 & 100 & 200 & 1.000 \\
\hline & 144 & 48 & & 24 & 48 & 240 \\
\hline \multirow{3}{*}{$\begin{array}{c}\text { pasar 5 } \\
\text { dari pembudidaya } \\
\text { dari konsumen } \\
\text { Margin Pemasaran(MP) }\end{array}$} & 760 & 952 & 1712 & 1520 & 1900 & 3040 \\
\hline & 1.000 & 1.500 & 2.000 & 2.000 & 2.500 & 4.000 \\
\hline & 240 & 548 & 288 & 480 & 600 & 960 \\
\hline \multirow{3}{*}{$\begin{array}{c}\text { PASAR 6 } \\
\text { dari pembudidaya } \\
\text { dari konsumen } \\
\text { Margin Pemasaran(MP) }\end{array}$} & 456 & 1520 & 2660 & 456 & 7.600 & 11400 \\
\hline & 600 & 2.000 & 3.500 & 600 & 10.000 & 15.000 \\
\hline & 144 & 480 & 840 & 144 & 2.400 & 3.600 \\
\hline
\end{tabular}

Sumber" Data pasar 2011 diolah

Berdasarkan tabel 4 tersebut maka margin pemasaran dapat dihitung berdasarkan biaya yang terkait dengan pemasaran (marketing cost) dan tingkat pengembalian dari faktor produksi, serta berapa yang diterima oleh pengumpul, pembudidaya dan lembaga pemasaran(lembaga tataniaga). Dengan demikian disimpulkan bahwa analisis margin pemasaran untuk mengukur pangsa pasar yang diterima oleh pembudidaya dari harga yang dibayarkan konsumen akhir, dilihat dari biaya penyaluran komoditas yang dikeluarkan oleh lembaga pemasaran, seperti biaya pengangkutan, biaya penimbangan, dan penyimpanan. Biaya biaya ini mungkin dilakukan dalam kegiatan budidaya. Selanjutnya margin keuntungan lembaga pemasaran komoditas perikanan dari produsen ke konsumen sesuai saluran-saluran distribusi yang dilakukan oleh lembaga pemasaran di enam lokasi pasar. Berikut perbandingan margin pemasaran ikan hias di enam pasar yang ada d kota/kabupaten Bogor, dengan asumsi bahwa saluran 1,2 dan 3 terdapat dalam perputaran ikan hias Koki dan Cupang yang ada dipasaran. 
Tabel 6: Rekapitulasi Marjin pemasaran dari saluran 1,2, dan 3 di enam pasar yaitu Depo Cibinong, Depo Baranang siang, Pasar Parung, Pasar Anyar, Pasar Dramaga dan pasar

\begin{tabular}{|c|l|c|c|c|c|c|c|}
\hline & & \multicolumn{3}{|c|}{ Koki } & \multicolumn{3}{c|}{ CUPANG } \\
\cline { 2 - 9 } & & saluran1 & saluran2 & saluran3 & saluran1 & saluran2 & saluran3 \\
\cline { 2 - 9 } Margin pemasaran (MP) & pasar 1 & 360 & 120 & 433 & 480 & 768 & 1200 \\
\cline { 2 - 9 } & Pasar2 & 2.400 & 800 & 4.850 & 720 & 1.080 & 1.800 \\
\cline { 2 - 9 } & Pasar3 & 144 & 48 & 592 & 24 & 48 & 240 \\
\cline { 2 - 9 } & Pasar 4 & 144 & 48 & 592 & 24 & 48 & 240 \\
\cline { 2 - 9 } & Pasar 5 & 20 & 548 & 288 & 480 & 600 & 960 \\
\cline { 2 - 9 } & Pasar 6 & 144 & 480 & 840 & 144 & 2.400 & 3.600 \\
\hline
\end{tabular}

Sumber : data pasar th 2011 diolah

Tabel 7 : Margin Pemasaran terendah dan tertinggi di 3 saluran pada Ikan koki dan Cupang

\begin{tabular}{|c|c|c|c|c|c|c|c|}
\hline \multirow{8}{*}{$\begin{array}{l}\text { marjin pemasaran } \\
\text { terendah }\end{array}$} & Pasar & \multicolumn{3}{|c|}{ Koki } & \multicolumn{3}{|c|}{ CUPANG } \\
\hline & & saluran1 & saluran2 & saluran3 & saluran1 & saluran2 & saluran3 \\
\hline & pasar 1 & & & & & & \\
\hline & Pasar2 & & & 4850 & & & \\
\hline & Pasar3 & & 48 & & 24 & 48 & \\
\hline & Pasar 4 & & 48 & & 24 & 48 & \\
\hline & Pasar 5 & & & & & & \\
\hline & Pasar 6 & & & & & & 3600 \\
\hline
\end{tabular}

Sumber: data Pasar th 2011 diolah

\section{Marjin Pemasaran (MP)}

berdasarkan tabel 5, 6 dan 7 tersebut diatas nampak berbagai tingkatan ada yang tinggi dan ada yang rendah, dari sini jelas terlihat bahwa Marjin Pemasaran tersendah ada pada posisi saluran 1,2 dan 3 pada pasar 3 pada komoditas ikan koki dan ikan Cupang yaitu berada pada tingkat marjin Pemasaran terendah sebesar Rp. 24; disaluran 1, Rp.48, berada pada saluran 2, dan terdapat pada pasar 3 dan 4 yaitu pasar Parung dan pasar Anyar, hal ini menunjukan bahwa komoditas ikan Cupang dan koki adalah merupakan jenis komoditas yang efisien untuk komoditas ikan hias; untuk Margin Pemasaran (MP) tertinggi berada pada posisi saluran 1,2 dan 3 di pasar 2 dan 6 , yaitu Margin Pemasaran sebesar RP.4.850 di saluran 3 pada pasar 2 yaitu pada Depo
Baranang Siang, dan margin pemasaran sebesar Rp.3.600 berada pada posisi saluran 3 di pasar 6 atau pasar Ciawi, yang berarti bahwa komoditas ikan hias koki menunjukan bahwa jenis ikan koki tidak efisien bagi sipembudidaya karena penerimaan pembudidaya lebih kecil dari pedagang pengumpul maupun pedagang besar.

\section{KESIMPULAN}

\section{Kesimpulan}

Kesimpulan dari penelitian ini adalah

1. Dapat terekapnya jumlah komoditas ikan hias, dengan berbagai kategori,diantaranya: 1) terdapat dua jenis ikan hias yang sama tetapi berbeda harga, di enam pasar, yaitu ikan Koki 
dan Ikan Cupang.; 2) terdapat satu jenis ikan yang sama berbeda harga di lima pasar yaitu ikan hias manfis dengan size ML dan M.;3) terdapat enam Jenis ikan yang sama tetapi harga berbeda pada empat pasar yaitu Oscar, Aligator,Neon Tetra, Rednos,Louhan, dan manfis indukan.;4) terdapat tujuh jenis ikan yang sama di tiga pasar yaitu yaitu Comet, Koy,Oskar albino,Palmas biru, Remon/lemon biru,Perot biasa dan Red Tails, dan 5), terdapat dua puluh tiga jenis ikan hias yang sama pada dua pasar, sisanya satu jenis ikan hias pada satu pasar.

2. Margin Pemasaran yang dihitung dari dua jenis ikan hias pada enam pasar menunjukkan bahwa marjin Pemasaran terendah sebesar Rp. 24; disaluran 1, Rp.48, berada pada saluran 2, dan terdapat pada pasar 3 dan 4 yaitu pasar Parung dan pasar Anyar, hal ini menunjukan bahwa komoditas ikan Cupang dan koki adalah merupakan jenis komoditas yang efisien untuk komoditas ikan hias tersebut. Untuk Margin Pemasaran (MP) tertinggi berada pada posisi saluran 3 di pasar 2 dan 6 , yaitu Margin Pemasaran sebesar RP.4.850 di saluran 3 pada pasar 2 yaitu pada Depo Baranang Siang, dan margin pemasaran sebesar Rp.3.600 berada pada posisi saluran 3 di pasar 6 atau pasar Ciawi, yang berarti bahwa komoditas ikan hias koki dan Cupang menunjukan jenis ikan hias yang tidak efisien bagi sipembudidaya, karena penerimaan pembudidaya lebih kecil dari pedagang pengumpul maupun pedagang/ pemasaran ikan besar.

\section{Saran}

1. Jika dilihat dari perhitungan margin pemasaran ikan hias terutama disaluran 2 dan 6, maka harga ikan hias Koki dan Cupang di pembudidaya perlu ada kesepakatan untuk peningkatan harga dari semua saluran distribusi.

2. Margin keuntungan ikan hias bagi sipembudidaya masih dibawah standar, oleh karena itu perlu adanya turun tangan dari steak holder ataupun pihak pemerintah untuk membantu meningkatkan keuntungan guna meningkatkan pendapatan para pembudidaya

3. Perlu adanya campur tangan pemerintah dalam penetapan harga ikan hias terutama ikan Koki dan Cupang.

4. Perlu adanya sosialisasi dan penyuluhan terhadap pembudidaya tentang harga ikan hias dan margin pemasaran ikan hias.

\section{DAFTAR PUSTAKA}

Abd.Rahim, (2002), Pengantar Teori dan Kasus Ekonomika Pertanian, cetakan 1 penerbi Penebar Swadaya, Jakarta

Bashu Swastha, (2002), Pengantar Bisnis Modern (pengantar Ekonomi Perusahaan Modern), Penerbit Liberty Yogyakarta

Cramer,GL,and L.W. Jensen (1997), Agricultural Economics and agribusiness, An Introduction, JOWA state Univ. Press

D.R.D Hastuti, (2007), Ekonomika Pertanian, penerbit Penebar Swadaya, Jakarta 
Darlymple DJ dan LJ Parsons (1983), Masri Singarimbun,(2000), Metode Marketing Manajement(strategy and Cases), John Wiley and Sons, New Penelitian Survey, Penerbit LP3ES, York. 